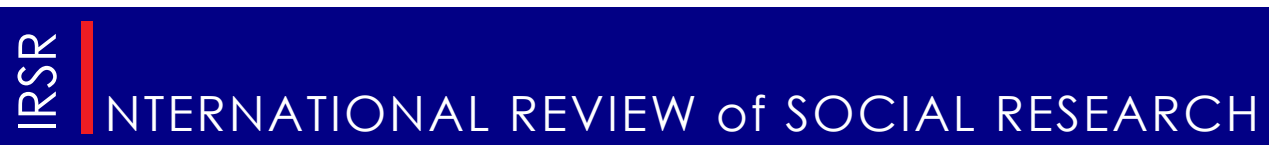

Volume 3, Issue 2, June 2013, 113-129

International Review of Social Research

\title{
Health Champions and Their Circles of Influence as a \\ Communication Mechanism for Health Promotion
}

\author{
Louise WARWICK-BOOTH \\ Ruth CROSS \\ James WOODALL \\ Rhiannon DAY \\ Jane SOUTH \\ Centre for Health Promotion Research, \\ Leeds Metropolitan University
}

\begin{abstract}
Health Champions are a growing component within the British public health workforce and their roles are now emphasised within the coalition's Government's public health strategy. However, there is the need for further exploration of the way in which Health Champions use interpersonal communication within their roles. This paper reports on the findings from a mixed method evaluation of one Health Champion programme in North East England. A key finding was the way in which Health Champions used circles of influence to communicate health knowledge and to try to achieve behaviour change, starting with themselves in the centre of their circle and then moving outwards to influence others such as family, friends and colleagues through their social networks. The paper argues that health champions act as healthy role models within their own circles of influence to successfully communicate health knowledge to those around them.
\end{abstract}

Keywords: Health champions, communication, empathy, role models, peer education.

\section{Introduction}

Health Champions are a growing component within the British public health system with their increasing contributions to community health and well-being being now emphasised within the coalition's Government's public health policy (Secretary of State for Health, 2010) and national guidance (NICE 2008; NHS Confederation and Altogether Better, 2012) indicating that they are viewed as important in contributing to health. Health

e-mail: L.Warwick-Booth@leedsmet.ac.uk. Acknowledgements: This study was part of an evaluation of the Sunderland Health Champion's Programme, commissioned by Sunderland tPCT. However the views expressed are those of the authors. 
Champion and community Health Champion Programmes encompass a variety of strategies and approaches to improving both population health and well-being. Health Champion roles are primarily undertaken by lay people which has led to suggestions that the concept of 'health champions' is not new but rather is a rebadging of lay involvement (South et al., 2010a). The National Institute for Health and Clinical Excellence (NICE 2008:40) defines Health Champions as people who have the experience and skills to engage and encourage others, both individually and at the level of the community in health promotion campaigns. While there is considerable diversity in public health practice within the UK (South et al., 2010a), there has been a tendency for the community champion role to be framed in terms of volunteering and active citizenship (NHS Confederation and Altogether Better, 2012). Nonetheless there are health champion programmes developed for workplace as well as community settings (Robinson et al 2010). The government's public health strategy acknowledges the benefits of community Health Champion roles in outlining the contribution that lay public health workers can make within local communities (Secretary of State for Health, 2010). Whilst the positive contributions that health champions can make are discussed within the literature, there is a lack of analysis in relation to the communication strategies that are being used by champions in performing their roles.

This paper reports on one Health Champion programme in North East England, focusing upon the ways in which health champions informally communicate and use networks. A broader evaluation was conducted which looked at the wider impacts of the programme (Warwick-Booth et al., 2012).

\section{The Sunderland Health Champion Programme}

The health champions programme that is the subject of this paper emerged in the context of significant health inequalities within the Sunderland area, (NHS South of Tyne and Wear and Sunderland City Council, 2011), and a commitment and vision articulated in the NHS Sunderland Teaching Primary Care Trust Integrated Strategic Operational Plan 2011-2015 to reduce these. Part of that vision is to shift the balance from treating illness to helping and supporting individuals to live longer and healthier lives. One strategy to achieve this is the Health Champion programme.

The strategic aim of the Sunderland Health Champions Programme is to improve the health of all disadvantaged communities in Sunderland by developing the health champions role as a mechanism to support local people in positively addressing both health determinants and accessing appropriate services. The Sunderland Health Champions Programme aims to address health inequalities and ultimately shift culture in relation to health by utilising and expanding Health Champions' circles of influence (self, family and friends, clients and the wider community) as a strategy to improve health. It is this approach to health communication that is explored within this paper. 
This Health Champion programme is taking a unique approach to developing capacity for delivery in that the training provided is not exclusive to volunteers, but is also available to frontline employees working for the local authority and within other workplaces. Health Champions undertake five training modules, offered by different training providers including:

- Understanding Health Improvement: This is a Royal Society for Public Health (RSPH) approved course that provides individuals with the underpinning knowledge and understanding of the benefits of good health and well-being. It aims to equip people with the knowledge and understanding of the principles of promoting health and well-being and to develop the public health skills to support lifestyle changes.

- Emotional Health and Resilience: a course to support frontline staff or volunteers on how to promote emotional resilience in others.

- Financial Capability: a course for frontline staff and volunteers to enable them to support and signpost people experiencing financial difficulties.

- Smoking Brief Intervention: a course training people to conduct brief interventions and to provide very brief advice in relation to smoking cessation.

- Alcohol Brief Intervention: a course training people to conduct brief interventions and to provide advice in relation to alcohol consumption, as well as training in relation to appropriate referral where necessary.
Whilst the training does not focus upon communication, the ethos of the programme and its overarching aim is to communicate via existing 'circles of influence' for example friends, family, clients and neighbours as the starting point for health education and improvement upon completion of the training programme. Therefore the programme while implemented in workplaces has an orientation to the community settings where many front line staff participating in the programme both live and work. Whilst there may be a contradiction in the role of Health Champions using an informal approach within a range of settings such as personal and governmental, the ways in which these roles supported or constrained each other is not explored within the focus of this paper. Rather, the circles of influence approach and the ways in which Health Champions communicated is reported here.

\section{Methodology}

The evaluation of the Sunderland Health Champions training programme was conducted in order to explore the ways in which Health Champions contribute to health improvement within the Sunderland area. The primary aim of the evaluation was to examine how well the programme was meeting its existing objectives and to quantify its impact upon teams, services, organisations and communities. The specific purpose was to assess the two core objectives of the programme:

a) To examine whether raising health awareness and promoting lifestyle change amongst training participants was taking place, 
b) To examine how staff, volunteers and community organisations are identifying and acting upon opportunities to promote health with the service users with whom they have routine contact.

This paper reports upon objective $b$ as it analyses the circle of influence approach that underpins the Sunderland Health Champions Programme, exploring how these circles are used as a mechanism to communicate health information and to encourage behaviour change.

The evaluation used a Theory of Change framework (Connell and Kubisch, 1988) to explore how health awareness was raised and how lifestyle change was then promoted amongst trainers, volunteers and community organisations. A theory of change is used to document and describe progress made towards outcomes within any given intervention. Theory of change approaches are used in evaluations of complex community interventions, such as the Sunderland Health Champion's Programme, as they allow for the exploration of why and how interventions work (Weiss, 1995). The evaluation used a mixed method design, combining qualitative and quantitative data collection and analysis, in an approach that has become increasingly accepted in health promotion research (Green and South, 2006).

\section{Methods}

The qualitative component of the research began with individual semi-structured interviews being conducted with key stakeholders who had developed and delivered the programme. Semi structured interviewswere carried out by the research team to direct discussion around a number of key themes comprising: involvement in the programme, perceptions of the role, motivations for doing the training, recruitment processes, support and impacts on individual, community and public health. Interviews were usually carried out face to face throughout January and February 2012. However, three telephone interviews were carried out with stakeholders who were not able to meet in person due to time constraints.

In addition to the qualitative interviews, four focus groups were carried out during January 2012 to capture the views of the Health Champions themselves. Given the variety of contexts in which the Sunderland Health Champions are working, it was necessary to differentiate and compare views of champions within statutory and third sector organisations and those volunteering. Thus participants from each of these sectors were invited to separate focus groups. During the focus groups the research team facilitated discussion around key themes including: how training was used, motivations for doing the training, support received and impact of the training on themselves and others.

The quantitative component of the evaluation was a questionnaire, administered online and sent to all Health Champions. The questionnaire covered key variables related to the characteristics of the Health Champions, the contexts in which they were working and/or volunteering, their views on the training and 
its impact. The questionnaire was administered using SNAP 10 and paper-based questionnaires were also made available to Champions upon request. Champions completed the questionnaire within their own time.

\section{Sampling}

Purposive sampling was used throughout the data collection. Within the qualitative interviews a list of 38 key stakeholders for the programme devised by Sunderland Teaching Primary Care Trust was used as the sampling frame to select interviewees. 22 consented to participate in a sample that consisted of PCT leads and staff involved in the implementation and operation of the training programme, individuals who formed the local government committee responsible for overseeing programme development, training deliverers, managers of Health Champions from the statutory, voluntary and community sectors and 'wider stakeholders' to give their views on the wider picture of the strategy.

A database containing all of the champions who had successfully completed their training and consented to the PCT to take part in the evaluation (144 Health Champions) was also provided to the evaluation team by Sunderland Teaching Primary Care Trust. Consequently, all Health Champions were invited to participate in the focus groups. 33 Champions participated across four focus groups. The same Health Champions were also included in the sample for the questionnaire; quantitative data were gathered through a small scale questionnaire which was sent to all 144 Health Champions. A total of 58 surveys were returned: 52 online and six paper submissions $(40 \%$ response rate).

\section{Ethics}

Ethical approval to conduct this study was obtained through the University research ethics process. Informed consent was obtained from all participants prior to digitally recording all interviews and focus groups. Confidentiality and anonymity was

Table 1. Overview of the data collection for the Sunderland Health Champion Evaluation

\begin{tabular}{|c|c|c|}
\hline Aspect of the data collection & Sampling frame & Total respondents \\
\hline $\begin{array}{l}\text { Qualitative semi-structured } \\
\text { interviews }\end{array}$ & 38 key stakeholders & $\begin{array}{c}\text { tPCT staff } 6 \\
\text { Area committees/Task and Finish } \\
\text { Group } 4 \\
\text { Training Deliverers } 4 \\
\text { Managers of Health Champions } 6 \\
\text { Wider stakeholders } 2 \\
\text { TOTAL } 22 \text { interviews }\end{array}$ \\
\hline $\begin{array}{l}\text { Qualitative semi-structured } \\
\text { focus groups }\end{array}$ & 144 Health Champions & $\begin{array}{c}\text { Statutory Sector Health } \\
\text { Champions } 16 \\
\text { Voluntary/Community Sector } \\
\text { Health Champions } 17 \\
\text { TOTAL } 33 \text { health champions }\end{array}$ \\
\hline Quantitative questionnaire & 144 Health Champions & $\begin{array}{l}\text { TOTAL } 58 \text { completed } \\
\text { questionnaires }\end{array}$ \\
\hline
\end{tabular}


assured across all methods used and the participant's right to withdraw without prejudice was clearly expressed to each. All quotations used in this paper are anonymised, differentiating participants only as either Health Champions or stakeholders.

\section{Analysis}

Data was analysed in the following way: all qualitative data were transcribed verbatim and then initially read and re-read by the research team to ensure familiarity with the content of the transcripts (JW, RC, and RD). Initial coding was undertaken in order to develop a coding framework using an inductive approach to identify the full range of emerging themes from the data. The coding framework was then applied to each transcript, with data subsequently organised into major thematic categories and sub categories. Themes were discussed and agreed within the research team. The quantitative data from the questionnaire was exported from SNAP 10 to Excel and SPSS 19. Multiple choice variables were recoded from binary codes and frequency counts were generated with the production of frequency graphs and tables; these were used to display the data. The findings here present a synthesis of the key themes in relation to the ways in which the health champions used communication strategies as part of their work.

\section{Results}

Modes of communication communication strategies to promote health within the 'circle of influence,
The qualitative data suggest that, in most cases, positive changes to family and friends' health behaviours were promoted through informal conversations, where the emphasis were on providing knowledge and information informally and letting family and friends make their own lifestyle choices:

'It's giving them [friends and family] the opportunity to change if that's what they want to do and giving them the advice and possibly the statistics you know about the smoking and the diet and the drinking, you know so they can see what they're doing to themselves and things like that, so it's definitely I think educating them even if they decided at the end of the day they don't want to change, they can think about it.' (Health Champion)

The questionnaire data confirmed this, as almost two-thirds of the Health Champions had used what they had learned in the training programme to try to improve the health of their family or friends. Health Champions also discussed how they used persuasion within their communication approaches, as a mechanism to try to promote behaviour change. One Health Champion, for example, who had participated in the alcohol brief intervention training, had raised awareness about the strength of certain drinks with his close friends in the pub:

'I did go out a month ago with the friends we meet up with once a month and we were sitting and I was telling them about the course and I said you're all sitting there with a Stella and you've got more 
units in that pint than that person there.... I don't know whether it stopped them drinking Stella but I told them what the difference was and it was the realisation.' (Health Champion)

The communications that Health Champions were involved with went beyond friends and family. More than half of the completed questionnaire responses included reports of using training within the wider community to signpost individuals to services. Moreover, there was a consensus that Health Champions were non-judgemental within their communications and not inclined to victim blame:

'That's often their experience when they go to the doctor, they're told off for their [lack of] exercise.' (Key Stakeholder, commenting also as a Health Champion)

\section{Health Champions as Health Role Models}

Health Champions acted as role models in a number of ways as part of their communication approach. Stories were told regarding alcohol use for example, about Health Champions cutting down their own intake alongside trying to support their friends to do so. In the case of smoking one Health Champion highlighted her role in helping her sister to quit and recognised the impact that her own personal success at quitting had had:

'I think I had done it informally because I am an ex-smoker myself.' (Health Champion)

The Health Champions acting as health role models functioned on an informal level through mechanisms of family relationships and friendship, using notions of both empathy and authenticity:

'I'm not a counsellor but sometimes just something quick can get them relaxed and talking about things, then you signpost them on.' (Health Champion)

Health Champions having a less professional role were also seen as more accessible than health professionals and able to spend more time with people to listen to their issues and concerns.

$$
\begin{aligned}
& \text { '...we're probably more } \\
& \text { approachable than your GP } \\
& \text { because your GP has a five minute } \\
& \text { slot with you, you know, and } \\
& \text { you're made to feel that you're } \\
& \text { taking up a GP's time.' (Key } \\
& \text { Stakeholder, commenting also as } \\
& \text { a Health Champion). }
\end{aligned}
$$

The Importance of Empathy and Authentic Engagement

Health Champions reported having increased success in supporting individuals where there was mutual understanding of the health issues concerned. In addition, qualities such as being able to listen to people and being personable and warm were highlighted as important:
'A good Health Champion is a people person, they understand when is the right time to be saying things and when it's not...' (Health Champion) 


\section{Personal Impact}

Whilst the focus of the Health Champion training was to contribute to raising awareness about health issues in others the health champions reported that it had made a tangible difference to their own health and wellbeing (full details about the personal impact of the health champion programme are reported in another paper by Woodall et al, forthcoming). The benefits to the Health Champions themselves were highlighted by the data from the stakeholder interviews. In the survey $83 \%$ of the respondents reported that they felt more confident to make changes in their own health and there were several stories of specific changes which Health Champions had made to, for example, their personal alcohol use and coping with stress. This resulted in a more empathetic approach whereby the Health Champion themselves were able to connect with the people they engage with on a more meaningful level having 'been there themselves'. They appreciated the challenges and difficulties inherent in personal health behaviour change as well as feeling more able to take control over their lives:

'The lifestyle I had pre this course is gone, I've got a different lifestyle.' (Health Champion)

\section{Health Champions as Peer Educators}

The importance of the location of Health Champion's as community members was recognised by a stakeholder:

'I think that if in public health if we're wanting to change health behaviours, then the only way to do it is to get the community to change it themselves because it's the only way it's going to work. We need to engage with the community and the Health Champions programme is doing that.' (Key stakeholder)

The role of peer education from insiders then was important in communicating health messages through the circles of influence. In the questionnaire data $70 \%$ of the Health Champions reported that they found it easy to create opportunities for applying what they had learnt to improve the health of others. The Health Champions reported many cases of success in helping friends and family modify their health behaviour whilst also acknowledging the limits of their knowledge.

\section{'Making every contact count'}

In the Sunderland context, many Health Champions were utilising their training to support people in their dayto-day work, especially with clients and service users who they came into contact with. This was reflected in the questionnaire findings where $81.1 \%$ of respondents felt 'confident' or 'very confident' in applying what they had learned with clients, customers or service users. Indeed, the majority of Health Champions commented that the training and skills gained from the programme complemented their day-to-day role and allowed them to signpost and identify issues more effectively. This was succinctly summarised by one Health Champion:

$$
\begin{aligned}
& \text { '...we're all doing our jobs and } \\
& \text { then now we're also Health } \\
& \text { Champions. It doesn't mean }
\end{aligned}
$$


that we're doing an extra job, it just means that we've got the knowledge and the understanding and the skills to signpost people to services...I think that's a real positive outcome of the Health Champions programme, is that now people have up-to-date information on key health issues.' (Health Champion)

\section{Discussion}

The circles of influence approach to communication was a strategy embodied within the Sunderland Health Champion Programme from its inception. The programme emphasised existing networks as a resource through which to communicate health improvement. Figure 1 below represents the concept

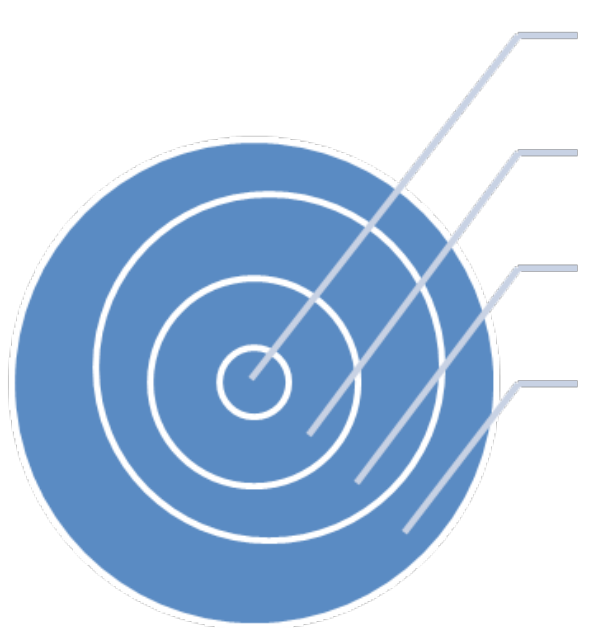

Individual

Family

Friends

Influence travels outwards, starting at the centre of the circle and moving towards Colleagues the outer layers through social and clients networks and connections.

Figure 1: Circles of Influence Diagram

of communication using circles of influence.

Tapping into existing social networks is recognised as a useful approach within the health promotion literature in that communication methods involving communities and individuals, which are 'bottom-up' are essential in enabling people to take control of their own health (Cross et al. forthcoming) and to improve their access to services (American Association of Diabetes Educators, 2003). Whilst some literature demonstrates that social networks can lead to negative health outcomes such as increased obesity (see Christakis and Fowler, 2007), the Sunderland Health
Champion approach to communication seeks to tap into local circles and networks as a starting point to improve health. Indeed, Health Champions talked confidently about the impact they had made within their own 'circle of influence', with friends and family members of Health Champions often the primary beneficiaries of the Champions' new knowledge. This would usually manifest in raising awareness of health issues, like poor diet, smoking and excessive alcohol levels. The qualitative data also suggested that changes to behaviour were promoted using informal strategies such as conversation.

Health Champions used persuasive 
communication within a variety of contexts. Persuasive communications are considered a mechanism to get individuals to engage in healthier behaviours, via prompting internal cues (O'Keefe, 1990). The persuasive communication strategies employed by Health Champions were often spontaneous in nature rather than being predetermined within their immediate circle of influence. This has been reported elsewhere in an evaluation of a Community Health Champion programme in Yorkshire and Humber, where Health Champions promoted health through talking to people informally as part of their daily lives (White et al., 2010).

The communication and associated impact that Health Champions made went beyond friends and family. This finding supports the growing evidence base that shows the benefit of community Health Champions in influencing the health of the wider community (Woodall et al., 2012, South et al., 2010b). This fits with North American research literature on lay health advisor roles working through transmission of culturally appropriate information through social networks (McQuiston, Choi-Hevel et al., 2001; Rhodes, Foley et al., 2007). Interestingly, both the qualitative and quantitative findings suggest that Health Champions were less inclined to signpost their friends and family onto other services. Instead they saw their role as providing information and giving support informally as part of normal conversation and daily domestic activities. Conversely, signposting people to appropriate services within the area, as well as sharing their knowledge of health issues was widely acknowledged to be the primary way in which Health Champions supported members of the wider community. Yet, what was also clear was that Health Champions themselves recognised the boundaries of their signposting role and understood when professional guidance was needed. This understanding of 'role boundary' is particularly relevant in relation to people working in lay public health roles (South et al., 2010a).

Communication processes and dynamics between information giver and receiver are well-recognised as being essential for any strategy or approach that aims to promote health or change health behaviour (Green and Tones, 2010). Indeed, the developing evidence shows that culturally appropriate communication skills are imperative for undertaking the Health Champion role successfully (Woodall et al., 2012). Using non-specialist language that was jargon-free was regarded by Health Champions as critical for communicating a clear message to people within their circle of influence.

Victim blaming is a term frequently used within the health promotion literature referring to the ways in which those who are ill are blamed for their own health problems without recognition of the broader factors that influence health such as social and environmental determinants.

The findings also point to the potential for the Health Champions to be health role models. Bandura's (1986) Social Learning Theory proposes that people learn through observing other people and modelling their behaviours. This clearly has connections to the concept of circles of 
influence. Notably, some of the Health Champions had made significant changes in their own lives which, in and of themselves, had influenced friends and family to consider or make changes. This lends support to the principle of homophily which proposes that people are more likely to pay attention to, and be influenced by, people who are connected to them in some way or are more 'like them' (Windahl et al., 2008). In addition, if a similarity is perceived (either through being similar types of people or through having experienced similar sets of circumstances) then this increases the credibility of the person 'giving the message' (McDonald and Grove, 2001). The importance of the 'communicator' (in this case the Health Champion) in the health communication process cannot be underestimated. This communication was also linked to notions of leading by example or modelling changes in health behaviour, drawing upon both empathy and authenticity within this process.

Empathy is linked to the concept of the role model. Having experience of struggling with behaviour change (for example, attempting to give up smoking) not only gave credence but enabled a more empathetic approach. Empathy is often highlighted as an important component of effective health communication (Brown et al., 2011) and is about having the ability to understand someone else's situation (Thompson, 2011). In attempting to change behaviour via persuasive communication, Health Champions need credibility to operate. They achieved this by acting as role models and through their professional positions in some instances.
Furthermore, they felt able to gain trust and trustworthiness is an essential component of both credibility and authentic engagement (Clarke, 1999). The Health Champions often already had an established relationship and rapport with the people they interacted with (namely friends and family within their circles of influence). This facilitated authentic engagement. Empathy in this context was also about the Health Champions knowing their audience, which has been listed as one of the most important factors within successful persuasion as it heightens motivation to change (Weeks, 1995).

Health Champions also spoke of increased appreciation of the holistic nature of health. This also links to notions of empathy and resulted in a greater appreciation of how life issues are inter-related and the subsequent impact this has on people's health experience. A non-judgemental approach is linked to empathetic understanding. This, together with the lack of victimblaming, was seen as contrary to how health professionals are sometimes perceived. Indeed, several aspects of the Health Champion role were seen as being different to the roles of 'traditional' health professionals.

This is an important feature of the approach within circles of influence and links to the position of Health Champions as community insiders. The social model of health suggests that our individual health is affected by the context in which we live and how we make sense of the world. The sociological literature exploring health has for many years focused upon the ways in which insiders provide different understandings of the social world and has debated knowledge creation along 
the insider/outsider dichotomy. Indeed, insider experiences of health and illness are often used to provide a contrasting picture to compare to dominant medical views (see Furedi, 2008). In the context of communication, insiders such as Health Champions are in a different position to those who may be considered and judged as outsiders. This position is likely to advantage their communication as peer educators based upon the understanding that they hold as a result of their location inside a specific community (McQuiston, Choi-Hevel et al., 2001).

The Health Champions themselves emphasised their role in providing knowledge and information to enable an informed choice and firmly rejected the notion that they used compulsion in their approaches. This approach directly links to peer education which is defined as information-sharing and education by non-professional people who are typically within the same societal group (Finn's, 1981; Svenson, 1998). Peer education also uses people from similar backgrounds or circumstances to challenge existing ideas and behaviour (McDonald and Grove, 2001). Given this, the links between peer education methods and the Health Champion programme, although not formally acknowledged, are clear. Peer education theory proposes that people are more likely to pay attention to, and more readily accept, information from their peers. It commonly underpins methods for promoting health among young people, but also with groups that are at risk of social exclusion (e.g. Stevens 1994; Hunter and Power, 2002). Little has changed since arguments were put forward to suggest that the evidence base for the effectiveness of peer education needs strengthening (Harden et al., 1999) and it is apparent that the use of such approaches makes intuitive sense.

The informal nature of this type of peer education seen in the Health Champions programme is in contrast with the more formalised approach of many peer education programmes where specific messages are tailored to target audiences. Rather, positive change was promoted through informal conversations and chance contacts with friends, family and others for example, taking opportunities to talk to people at bus stops to promote awareness of health issues. The model of peer education most closely aligned with the Health Champions programme is therefore the Peer Influence Model. The Peer Influence Model highlights the effectiveness of education via informal, everyday encounters (McDonald and Grove, 2001). This is likely because Health Champions are more accessible than health professionals. The majority were front line workers or volunteers and therefore have much greater source credibility (Kreuter and McClure, 2004). The 'gap' which often exists between expert professionals and lay people is therefore significantly lessened.

The training and subsequent deployment of Health Champions within the community to promote health and well-being coincides with wider policy drivers to ensure that every contact that workers within the health field have with clients is an opportunity to promote health messages. Health Champions, many of whom were working for the local government services, were also encouraged to make 
'every contact a health improvement contact'. Some have described this as creating an 'extended sales force' for healthier living' (Ion, 2011) and commentators have argued that nonprofessional lay workers can make an important contribution to reducing health inequalities in society (PerezEscamilla, Hromi-Fiedler et al. 2008; Open Society Foundations, 2011). South, Branney et al. (2011) argue that the agency of volunteers in community health projects and their access to social networks enable them to act as bridges between disadvantaged communities and services.

\section{Limitations of the study}

The main limitation of this study is that it is not able to assess the effects of the communication strategies within the population that they were aimed at. Due to the informal nature of the communication strategies being used within the Sunderland approach, evaluators were not able to collect data from the targets of the intervention. It remains challenging to capture impact when health is being promoted both informally and using brief interventions.

A further limitation is that the evaluation was not able to measure and report the longitudinal effects of the Sunderland Health Champion Programme. Time and budget limitations made it impractical to assess the long-term impact of this programme, which may still continue after the intervention ends.

\section{Conclusion}

Ultimately, communication is central to the success of any health promotion initiative. It is at the 'forefront of the achievement of health promotion objectives' (Corcoran, 2007:1). Health communication is about communicating health messages that should help people to think about their health, the influences upon their health and what is needed in terms of behaviour change. Health messages have been criticised for being delivered in a top-down manner which is not always appropriate, information can be 'lost in translation', culturally insensitive and just does not appear relevant to those who it is trying to reach (Cross et al., forthcoming). In using a communication strategy linked to circles of influence as part of a broad strategy to improve health across the Sunderland area, Health Champions were able to communicate within their own networks tapping into empathy, authenticity and insider experiences to positively promote health through peer education. Some Health Champions also acted as healthy role models. This approach enabled Health Champions to work effectively within their 'circles of influence' and to provide information on health issues as well as signpost people effectively to services. Health Champions 'added value' by communicating through their circles of influence because of their accessibility and ability to engage with local people, using family and friends as a starting point for communication and then expanding further afield for example within work contexts. Health Champions also highlighted core communication attributes 
needed to be successful in such a role; listening, having empathy and being non-judgemental were all seen as key individual characteristics needed to effectively communicate on an interpersonal level and to fulfil the role of a Health Champion. The circles of influence approach to communication worked in Sunderland as an effective mode of communication to promote health using the connections of workers and volunteers close to the community, whilst fitting with current policy drivers such as Making Every Contact Count.

The Sunderland Health Champion evaluation highlighted an interesting mode of communication using circles of influence as a strategy to communicate health. Whilst evidence of short term communication changes have been made clear, it is important that medium and long term communication strategies and associated health outcomes are evaluated over time. Given that the communication strategy used by Sunderland Health Champions is informal, it is challenging to capture any related impacts associated with both the promotion of health in informal ways and the delivery of brief interventions. Future research needs to consider the ways in which health communication strategies such as circles of influence can contribute to increased health awareness and health improvement over longer periods of time and evaluate whether such a strategy is applicable in broader contexts, as well as whether it leads to longer term health impacts.

Given that the use of lay workers takes place within many contexts and countries (including those considered to be lower-income) and that these approaches have shown many benefits (Letwin et al., 2006), this approach using circles of influence is potentially useful elsewhere. Thus, future research also needs to consider the applicability of this mechanism of communication within broader lay health worker programmes.

\section{References}

American Association of Diabetes Educators (2003) 'Diabetes community health workers.' The Diabetes Educator, 29(5): 818, 821-814.

Bandura, A. (1986) Social Foundations of Thought and Action. Englewood Cliffs, NJ: Prentice-Hall.

Brown, T., Boyle, M., Williams, B., Molloy, A., Palermo, C., McKenna, L. and Molloy, L. (2011) 'Predictors of empathy in health science students.' Journal of Allied Health, 40 (3): 143-149.

Christakis, N. A. and Fowler, J. H. (2007) 'The spread of obesity in a large social network over 32 years' The New England Journal of Medicine 357 (4): 370-379.

Clarke, A. (1999) 'Changing attitudes through persuasive communication' Nursing Standard 13, (30): 45-47.

Connell, J. P. and A. C. Kubisch (1988) 'Applying a Theory of Change approach to the evaluation of Comprehensive Community Initiatives: progress, prospects and problems. New approaches to evaluating community initiatives.' In K. FulbrightAnderson, A. Kubisch and J. Connell (eds) Theory, measurement and analysis. Washington D. C: The Aspen Institute. 
Corcoran, N. (2007) Communicating Health, Strategies for Health Promotion. London: Sage.

Cross, R., O’Neil, I. and Dixey, R. (2013) ‘Communicating Health'. In: R. Dixey. (eds.) Health Promotion: Global Principles and Practice. Wallingford: CABI.

Finn, P. (1981) 'Teaching students to be lifelong peer educators'. Health Education, September/October, 13-16.

Furedi, F. (2008) Medicalisation in a therapy culture. In: Wainwright, D. (eds.) $A$ Sociology of Health. London: Sage, pp. 97-114.

Green, J. and South, J. (2006) Evaluation Buckingham: Open University Press. Green, J. and Tones, K. (2010) Health promotion. Planning and strategies.

London: Sage.

Harden, A., Weston, R. and Oakley, A. (1999) A review of the effectiveness and appropriateness of peer-delivered health promotion interventions for young people. London, EEPI-Centre, Institute of Education: University of London.

Hunter, G. and R. Power (2002) 'Involving Big Issue vendors in a peer education initiative to reduce drug-related harm: a feasibility study.'Drugs: Education, Prevention \& Policy 9(1): 57-69.

Ion, V. (2011) 'Making every contact count: a simple yet effective idea'. Perspectives in Public Health, 131: 69-70.

Kreuter, M. W. and McClure, S. M. (2004) 'The Role of Culture in Health Communication.' Annual Review of Public Health, 25: 439-455.

Letwin, S. A., S. M. Babigumira, et al. (2006) Lay Health Workers in Primary and Community Health Care: A Systematic Review of Trials available at http://www. who.int/rpc/meetings/LHW_review.pdf (accessed 5th March 2013).

McDonald, J. and Grove, J. (2003) Youth for Youth: Piecing together the Peer Education Jigsaw. NCETA, Drug and Alcohol Services, Council of South Australia.

McQuiston, C., S. Choi-Hevel, et al. (2001) 'Protegiendo Nuestra Comunidad: empowerment participatory education for HIV prevention.' Journal of Transcultural Nursing 12(4): 275-283.

National Institute for Health and Clinical Effectiveness (2008) Community engagement to improve health.NICE public health guidance 9. London: NICE. NHS Confederation and Altogether Better (2012) Community Health Champions: creating new relationships with patients and communities. London: NHS Confederation.

O’Keefe, D. J. (1990) Persuasion Newbury Park, CA: Sage.

Open Society Foundations (2011) Roma Health Mediators: Successes and Challenges. New York: Open Society Foundations.

Perez-Escamilla, R., A. Hromi-Fiedler, et al. (2008) 'Impact of peer nutrition education on dietary behaviors and health outcomes among Latinos: a systematic literature review.' Journal of Nutrition Education and Behavior 40(4): 208-225. Rhodes, S. D., K. L. Foley, et al. (2007) 'Lay health advisor interventions among hispanics/latinos a qualitative systematic review.' American Journal of Preventive Medicine 33(5): 418-427. 
Robinson, M., South, J. and Kinsella, K. (2010) Altogether Better Thematic Evaluation-Mental Health and Employment Projects.Leeds: Centre for Health Promotion Research, Leeds Metropolitan University.

Secretary of State for Health. (2010) Healthy Lives, Healthy People: Our Strategy for Public Health in England. London: Stationary Office.

South, J., Meah, A., Bagnall, A. -M., Kinsella, K., Branney, P., White, J. and Gamsu, M. (2010a) People in Public Health - a study of approaches to develop and support people in public health roles. Final report. London: NIHR Service Delivery and Organisation programme.

South, J., White, J. and Woodall, J. (2010b) Altogether Better - Community Health Champion role and empowerment. Thematic evaluation summary. Leeds: Centre for Health Promotion Research, Leeds Metropolitan University.

South, J., P. Branney, et al. (2011) 'Citizens bridging the gap? Interpretations of volunteering roles in two public health projects.' Voluntary Sector Review 2(3): 297-315.

Stevens, P. E. (1994) 'HIV prevention education for lesbians and bisexual women: a cultural analysis of a community intervention.'Social Science and Medicine 39(11): 1565-1578.

Sunderland Data Annex-NHS South of Tyne and Wear and Sunderland City Council (2011) Chapter 4: Life Expectancy And Mortality And Ill Health From All Causes in Sunderland Joint Strategic Needs Assessment 2011, Data Annex. Version 4QAd, 229-260.

Svenson, G.R. (1998) European guidelines for youth AIDS peer education.

Sweden, European Commission.

Thompson, N. (2011) Effective Communication: A Guide for the People

Professions. 2nd Ed. Maidenhead, Palgrave MacMillan.

Warwick-Booth, Woodall, J, South, J. et al. (2012) An Evaluation of Sunderland Health Champions Programme. Leeds: Centre for Health Promotion Research, Leeds Metropolitan University.

Weeks, S. (1995) Health education: learning the techniques of persuasion' Professional Care of Mother and Child, 5, (2): 53-55.

Weiss, C. H. (1995) 'Nothing as Practical as Good Theory: Exploring Theorybased Evaluation for Comprehensive Community Initiatives for Children and Families.' In J. Connell et al.(eds) New Approaches to Evaluating Community Initiatives: Concepts, Methods, and Contexts, Washington, DC: Aspen Institute. White, J., South, J., Woodall, J. and Kinsella, K. (2010) Altogether Better thematic evaluation - community health champions and empowerment. Leeds: Centre for Health Promotion Research, Leeds Metropolitan University.

Windahl, S., Signitzer, B. and Olson, J. T. (2008) Using Communication Theory. London, Sage.

Woodall, J., Kinsella, K., South, J. and White, J. (2012) Older volunteers in health and well-being: a review of the evidence. Leeds: Centre for Health Promotion Research, Leeds Metropolitan University.

Woodall, J., White, J. and South, J. (2012) 'Improving health and well-being 
through community health champions: a thematic evaluation of a programme in Yorkshire and Humber.'Perspectives in Public Health. Published online $13^{\text {th }}$ August 2012 DOI: 10.1177/1757913912453669. 
